\title{
Alguns aspectos do ensino e aprendizagem de radioatividade em periódicos nacionais e internacionais
}

some aspects related to the teaching and learning of radioactivity in

national and international journals

\author{
Flávia Cristiane Vieira da Silva | UFRPE \\ Angela Fernandes Campos | UFPE \\ Maria Angela Vasconcelos de Almeida | UFPE
}

\section{Resumo}

Este estudo investigou alguns aspectos do ensino e aprendizagem de radioatividade em periódicos nacionais e internacionais de Ensino de Ciências entre os anos de 1990 e 2012. Para análise dos artigos estabeleceu-se categorias a priori disponíveis na literatura. Duas tendências de pesquisa foram identificadas: (i)- proposta de material didático/ proposta e análise de estratégias didáticas que incluem analogias, modelos, jogos ou módulos didáticos; (ii)- concepções alternativas dos estudantes/análise de livro didático. No primeiro caso, o estudo realizado sugere a necessidade dos professores, em diferentes níveis de ensino, terem acesso às estratégias didáticas propostas nos periódicos analisados pelas contribuições que podem dar para a prática docente; e no segundo caso, a quantidade restrita de trabalhos sobre as concepções alternativas dos estudantes e de análise de conceitos relacionados com radioatividade em livros-texto de Química, aponta para o desenvolvimento de um maior número de investigações nessa direção, particularmente voltadas para o Ensino Superior de Química.

Palavras-Chave: Ensino, aprendizagem, radioatividade.

\section{Abstract}

This study investigated a number of aspects related to the teaching and learning of radioactivity in national and international science education journals between 1990 and 2012. Categories available in the literature were established a priori for analysis of the articles. Two research tendencies were identified: proposal of didactic material/proposal and analysis of didactic strategies that included analogies, models, games or didactic modules; and alternative concepts of the students/analysis of didactic textbooks. In the first case, the study suggests the need for professors at different teaching levels to have access to the didactic strategies proposed in the journals analyzed, owing to their potential contributions to teaching practices; and in the second case, the restricted number of studies on alternative students' concepts and analysis of radioactivity-related concepts in chemistry textbooks points to the need for research in that area, particularly directed towards undergraduate courses.

Keywords: Teaching, learning, radioactivity. 


\section{Introdução}

O tema radioatividade é parte integrante dos currículos do ensino médio e superior de Química no Brasil; é um tema atual, sendo recomendado nas orientações curriculares oficiais (BRASIL, 2006), como potencial para a elaboração de práticas pedagógicas que possibilitem o desenvolvimento de competências diversas, como representação e comunicação, investigação e compreensão, contextualização sociocultural.

O estudo da radioatividade envolve questões atuais da sociedade, tais como: energia, meio ambiente, acidentes nucleares, lixo atômico, medicina, entre outros, além de ser fundamental para compreensão da estrutura do átomo, contemplando diversas áreas de ensino, dentre elas o ensino de Ciências com maior ênfase na Física e na Química. Tekin e Nakiboglu (2006) comentam que a Física e a Química Nuclear podem ser vistas como uma Ciência Nuclear e que os estudos advindos dessa Ciência contribuíram significativamente para o entendimento da natureza da matéria e, consequentemente, trouxeram benefícios para medicina, eletrônica, geologia, arqueologia e indústria. Em contraposição a isso, eles, a partir do exame dos livros didáticos, inferem que muito pouco da Química nuclear é abordada em sala de aula, em particular, no ensino médio. Algumas razões são apontadas: decisões curriculares, nas quais o assunto é considerado sem importância para os estudantes; os autores de livros didáticos apresentarem o conteúdo de radioatividade nos últimos capítulos do livro de Química e a deficitária formação dos professores sobre esse conteúdo. As questões problemáticas trazidas no estudo de Tekin e Nakibog/u (2006) nos instigou a analisar que discussões os periódicos nacionais e internacionais trazem sobre o tema radioatividade. Sob essa perspectiva, esse estudo procurou responder a seguinte questão: que aspectos do ensino e aprendizagem de radioatividade as pesquisas nacionais e internacionais retratam? Nesse sentido, vale ressaltar que, o conhecimento das pesquisas sobre o ensino e aprendizagem de radioatividade contribui para a identificação das tendências de investigação, na qual possibilita aprofundamentos numa dada linha de pesquisa e novos desdobramentos de estudos nessa direção. Por exemplo, as dificuldades dos alunos com relação à compreensão de conceitos relacionados à radioatividade e as necessidades atuais de um ensino que contemple desenvolvimento científico, tecnológico e questões ambientais intrínsecas ao estudo da temática radioatividade são ponto de partida e facilitadores para o planejamento docente no sentido de elaboração de estratégias didáticas que levem em consideração tais questões. As dificuldades apontadas anteriormente inserem-se numa área de pesquisa da educação química denominada concepções alternativas, ou seja, ideias que os alunos trazem que são discordantes do que é consenso cientificamente (BOO, 1998). Além disso, os resultados aqui obtidos contribuem para a área de ensino de Ciências/Química, no sentido que, nacionalmente e na literatura internacional são escassos os trabalhos nessa direção (MEDEIROS e LOBATO, 2010, TEKIN e NAKIBOGLU, 2006). 


\section{Metodologia}

Este trabalho possui características de uma pesquisa bibliográfica. Este tipo de pesquisa procura sistematizar e analisar descritiva e qualitativamente o conjunto de produções de uma determinada área, selecionados de acordo com os interesses e objetivo do pesquisador (SIQUEIRA, 2001; TEIXEIRA, 2006).

Para nosso estudo optamos por trabalhar com um recorte temporal na busca dos artigos nos periódicos nacionais e internacionais de ensino de Ciências, Química e Física, em um período compreendido entre 1990 a 2012, que estivessem disponíveis nos sites das revistas pesquisadas. Para isto, foi feita uma pesquisa em revistas de ensino de Química, Física e Ciências, classificados pela Coordenação de Aperfeiçoamento de Pessoal de nível Superior (CAPES) como Qualis ${ }^{1}$ A ou Qualis B. Inicialmente a busca por artigos referentes ao ensino e à aprendizagem de radioatividade envolveu periódicos nacionais específicos para o ensino de Química e de Ciências. Em um primeiro momento, foi realizado um estudo nos sites dos periódicos: Ciência \& Educação (Qualis A), ENSAIO: Pesquisa em Educação em Ciências (Qualis A); Investigações em Ensino de Ciências (Qualis A); Experiências em Ensino de Ciências (Qualis B); Química Nova na Escola (Qualis B) e Química Nova (Qualis B), entre os meses de junho a julho de 2011 por meio de palavras-chave: Química Nuclear, radioatividade, radiação, nuclear. O estudo mostrou uma escassez de trabalhos relacionados à Química Nuclear o que nos fez iniciar uma nova busca nos periódicos nacionais de Física, a saber, Caderno Brasileiro de Ensino de Física (Qualis B) e Física na Escola (Qualis B), durante o mês de agosto de 2011.

Mais uma vez, poucos estudos foram encontrados, sendo a pesquisa expandida, incluindo-se outros periódicos nacionais (Revista Brasileira de Pesquisa em Educação em Ciências, Revista Brasileira de Ensino de Física) e internacionais (inglês e espanhol).

Essa nova busca por artigos em revistas nacionais foi feita através da leitura dos títulos e de alguns resumos em todos os números disponíveis no site dos periódicos.

Dentre os periódicos pesquisados as revistas Experiências em Ensino de Ciências (12 números de 2006 a 2011), Química Nova na Escola (42 números de 1995 a 2012), Química Nova (158 números de 1990 a 2012); Revista Brasileira de Pesquisa em Educação em Ciências (32 números de 2001 a 2011); Revista Brasileira de Ensino de Física (42 números de 1990 a 2012), não apresentaram resultados referentes a ensino e aprendizagem de radioatividade.

A pesquisa internacional, que envolveu os periódicos Journal of Chemical Education ${ }^{2}$ (Qualis A) International Journal of Science Education (Qualis A); Journal of Research in Science Teaching (Qualis A), Enseñanza de Las Ciências (Qualis A), Revista Educación

\footnotetext{
${ }^{1}$ Qualis é o conjunto de procedimentos utilizados pela CAPES para estratificação da qualidade da produção intelectual dos programas de pós-graduação, afere a qualidade dos artigos e de outros tipos de produção, a partir da análise da qualidade dos veículos de divulgação, ou seja, periódicos científicos.
} 
Química (Qualis B) e Revista Eletrônica de Enseñanza de Las Ciências (Qualis A), foi realizada a partir da consulta ao portal de periódicos da CAPES, entre os meses de fevereiro e abril de 2012. Essa pesquisa, também foi feita a partir da leitura dos títulos e de alguns resumos dos artigos, que apresentassem as palavras-chave supracitadas referentes à temática, em todos os volumes e números das revistas selecionadas. As revistas Journal of Research in Science Teaching (222 números de 1990 a 2012) e Revista Eletrônica de Enseñanza de Las Ciências (33 números de 2002 a 2012), não apresentaram resultados referentes a ensino e aprendizagem de radioatividade. Os periódicos pesquisados que apresentaram resultados, bem como os números analisados e o número de artigos encontrados são apresentados na Tabela 1:

Tabela 1: Resultado do Levantamento de artigos nos respectivos periódicos

\begin{tabular}{|c|c|c|c|}
\hline Periódico & Período pesquisado & $\begin{array}{l}\text { Números } \\
\text { analisados }\end{array}$ & $\begin{array}{c}\text { Número de artigos } \\
\text { encontrados }\end{array}$ \\
\hline Ciência \& Educação & $\begin{array}{c}\text { 1998-2011 } \\
\text { Obs: } 1999 \text { não houve publicação }\end{array}$ & 36 & 2 \\
\hline $\begin{array}{l}\text { Ensaio: Pesquisa em Educação } \\
\text { em Ciências }\end{array}$ & $1999-2011$ & 28 & 1 \\
\hline $\begin{array}{c}\text { Investigações em Ensino de } \\
\text { Ciências }\end{array}$ & 1996-2012 & 51 & 1 \\
\hline $\begin{array}{c}\text { Caderno Brasileiro de Ensino de } \\
\text { Física }\end{array}$ & 1990-2011 & 69 & 4 \\
\hline Física na Escola & $2000-2011$ & 23 & 1 \\
\hline Journal Of Chemical Education & 1990-2012 & 254 & 11 \\
\hline $\begin{array}{c}\text { International Journal of Science } \\
\text { Education }\end{array}$ & 1999-2012 & 193 & 3 \\
\hline $\begin{array}{c}\text { Revista Enseñanza de Las } \\
\text { Ciências }\end{array}$ & $1998-2012$ & 37 & 2 \\
\hline Revista Educación Química & 1990-2012 & 97 & 2 \\
\hline
\end{tabular}

\section{Categorias de análise dos artigos sobre ensino e aprendizagem de radioatividade}

Para a análise dos artigos, foram estabelecidas algumas categorias com base nos trabalhos de Costa e Moreira (1996). As categorias foram: objetivo/tema central, procurouse identificar qual o objetivo principal do artigo, além do tema abordado em relação à radioatividade; metodologia/fatores investigados, consistiu na identificação dos métodos, instrumentos, público alvo, além dos fatores investigados pelos autores e que estavam descritos no artigo; resultados/fatores relevantes/implicações educacionais, apresenta os principais resultados bem como as implicações educacionais trazidas pelos autores de acordo com o objetivo do artigo analisado; conclusões/considerações/sugestões, pontua aspectos relevantes sobre o ponto de vista dos autores em relação ao objetivo do artigo analisado. 


\section{Resultados e discussão}

\section{Análise dos artigos sobre ensino e aprendizagem de radioatividade}

No período escolhido para investigação, 1990-2012, foram encontrados 26 artigos sobre ensino e aprendizagem de radioatividade, nos periódicos selecionados. Dos 26 artigos, 12 são direcionados para o ensino de Química, 5 para o ensino de Ciências e 7 para o ensino de Física, sendo dois trabalhos direcionados para mais de uma área, um direcionado para Física e Química e o outro direcionado para Física, Química, Biologia e Historia. As tabelas 2 e 3 apresentam o resultado da análise dos artigos em relação às categorias definidas para este estudo que permitiu a identificação das tendências de investigação.

Tabela 2: Resultado da análise dos artigos referentes a categoria objetivo/tema central; metodologia/fatores investigados.

\begin{tabular}{|c|c|c|}
\hline $\begin{array}{l}\text { AUTOR(ES)/ } \\
\text { ANO }\end{array}$ & $\begin{array}{l}\text { OBJETIVO / } \\
\text { TEMA CENTRAL }\end{array}$ & $\begin{array}{l}\text { METODOLOGIA/ } \\
\text { FATORES INVESTIGADOS }\end{array}$ \\
\hline $\begin{array}{l}\text { 1. Samagaia e } \\
\text { Peduzzi, } 2004\end{array}$ & $\begin{array}{l}\text { Aplicar um módulo didático, elaborado } \\
\text { através da problematização sobre o } \\
\text { desenvolvimento e a utilização das } \\
\text { bombas nucleares; Fissão nuclear; } \\
\text { radiação, reação em cadeia, dentre } \\
\text { outros; }\end{array}$ & $\begin{array}{l}\text { Ensino fundamental; Elaboração de um } \\
\text { módulo didático; Jogos de papeis (RPG); } \\
\text { Decisão quanto a investir ou não em uma } \\
\text { verba bastante grande para o } \\
\text { desenvolvimento de projeto-construção de } \\
\text { super bomba; Entrevistas semiestruturadas. }\end{array}$ \\
\hline $\begin{array}{l}\text { 2. Sorpreso e } \\
\text { Almeida, } 2010\end{array}$ & $\begin{array}{l}\text { Compreender o imaginário de } \\
\text { licenciandos em física sobre a questão } \\
\text { nuclear, numa abordagem histórica em } \\
\text { situações nas quais se procurava pensar o } \\
\text { ensino médio; } \\
\text { Questão nuclear; }\end{array}$ & $\begin{array}{l}\text { Ensino Superior; Atividades com a temática } \\
\text { Questão Nuclear incluindo elementos da } \\
\text { historia da ciência na disciplina prática de } \\
\text { ensino de física e estagio supervisionado; } \\
\text { implicações para a formação de professores. }\end{array}$ \\
\hline $\begin{array}{l}\text { 3. Medeiros e } \\
\text { Lobato, } 2010\end{array}$ & $\begin{array}{l}\text { Analise do conteúdo radiação em livros } \\
\text { didáticos de Química e Física; Análise das } \\
\text { concepções prévias dos alunos sobre } \\
\text { radiação; Desenvolver e aplicar um } \\
\text { material didático para suporte ao ensino e } \\
\text { aprendizagem de radiação; Análise do } \\
\text { conhecimento adquirido pelos estudantes } \\
\text { após estudo do conteúdo; Radiação }\end{array}$ & $\begin{array}{l}\text { Ensino Médio; Seleção e analise de } 6 \text { livros do } \\
\text { PNLDEM e disponíveis para análise; } \\
\text { Questionário; Desenvolvimento de material } \\
\text { didático para abordar diversos tipos de } \\
\text { radiações presentes no cotidiano; Analise do } \\
\text { conhecimento adquirido após aplicação do } \\
\text { material didático. }\end{array}$ \\
\hline $\begin{array}{l}\text { 4. Vasconcelos } \\
\text { e Leão, } 2012\end{array}$ & $\begin{array}{l}\text { Elaboração e investigação de uma } \\
\text { estratégia didática com incorporação do } \\
\text { uso de vídeos e outros recursos } \\
\text { audiovisuais em sala de aula; } \\
\text { Radioatividade. }\end{array}$ & $\begin{array}{l}\text { Ensino Médio; Construção e aplicação de } \\
\text { uma Flexquest com tema radioatividade; }\end{array}$ \\
\hline $\begin{array}{l}\text { 5. Eichler, } \\
\text { Junges e Del- } \\
\text { Pino, } 2006\end{array}$ & $\begin{array}{l}\text { Descrever o software educativo Cidade do } \\
\text { átomo e indicar estratégia didática para } \\
\text { sua utilização; } \\
\text { Energia Nuclear }\end{array}$ & $\begin{array}{l}\text { Ensino Médio; Descreve o software que } \\
\text { aborda dentre outras coisas a utilização da } \\
\text { energia nuclear na produção de energia } \\
\text { elétrica. }\end{array}$ \\
\hline $\begin{array}{l}\text { 6. Schappo, } \\
2010 .\end{array}$ & $\begin{array}{l}\text { Apresentar uma analogia utilizada para } \\
\text { descrever os fenômenos de fissão e fusão } \\
\text { nuclear durante uma das aulas de um } \\
\text { minicurso intitulado: Energia Nuclear: } \\
\text { Solução ou Problema?; Energia Nuclear, } \\
\text { Estabilidade Nuclear, Fissão e Fusão. }\end{array}$ & $\begin{array}{l}\text { Ensino Médio; Apresenta a montagem do } \\
\text { modelo e a sua relação com o modelo } \\
\text { teórico. }\end{array}$ \\
\hline
\end{tabular}




\begin{tabular}{ll}
\hline $\begin{array}{l}\text { 7. Krapas e } \\
\text { Borges, 1998. }\end{array}$ & $\begin{array}{l}\text { Propor uma analogia para o } \\
\text { funcionamento do circuito RC baseado no } \\
\text { decaimento de uma amostra radioativa; } \\
\text { Decaimento radioativo }\end{array}$ \\
$\begin{array}{l}\text { Evidenciar aspectos do imaginário de } \\
\text { licenciando em Física, relacionados ao } \\
\text { Almeida, 2008 } \\
\text { trabalho com resolução de problemas e } \\
\text { com a inclusão da Física Nuclear no } \\
\text { Ensino Médio; Questão Nuclear. }\end{array}$ \\
$\begin{array}{ll}\text { 9. Soutrar que alguns temas de Física } \\
\text { Dantas, 2010. }\end{array}$ & $\begin{array}{l}\text { Nuclear podem ser abordados em nível } \\
\text { conceitual no ensino Médio; } \\
\text { Radioatividade, Física Nuclear. }\end{array}$ \\
10. Cordeiro e \\
Peduzzi, 2010.
\end{tabular}

12. Wu e Tsai, 2007.

Analisar o raciocínio dos alunos sobre o uso da energia nuclear; Energia Nuclear.
Analisar concepções de alunos, de um curso preparatório de professores, sobre as atitudes e os riscos associados com as radiações ionizantes; Radiação Ionizante.

Analisar atitudes dos estudantes

14. Tiburzi et universitários acerca do fenômeno al, 2004 radioativo, energia nuclear e suas aplicações; Radioatividade.

Investigar como se trata o tema energia 15. García- nuclear em relação a abordagem CTS em Carmona e textos de física e química na educação Criado, 2008. cientifica básica obrigatória; Energia nuclear.

Indagar o que pensam os alunos sobre

16. Gutierrez temas de física moderna, vinculados com et al, 2000. a radioatividade, a estrutura atômica e a energia nuclear

\section{Fortman, 1992. \\ Propor analogia para o decaimento beta}

18. Bonneau 1994. Descrever o desenvolvimento de atividades sobre o problema de resíduos radioativos.

19. Campbell, Apresentar regras simples para 1995.
Ensino Superior; A similaridade matemática entre os fenômenos do circuito RC e do decaimento radioativo

Ensino Superior; Acompanhou os alunos na disciplina de Prática de Ensino de Física e Estagio Supervisionado.

Ensino Médio; Apresentam de forma breve alguns conceitos referentes à radioatividade.

Ensino Médio; Apresentam algumas categorias para implicações educacionais ao se utilizar as conferencias: motivacional; histórico-epistemológicos e conceitual.

Ensino Médio; Questionário: Construção de usina nuclear; Entrevista semiestruturada (causa de um incidente - poluição da águaseria a usina nuclear);

Características dos estudantes.

Ensino Médio; Questionário: Concordam ou não com a construção de centros nucleares; Análise da capacidade de argumentar; Capacidade de contra-argumentar; Construção de contraprova; Analise de raciocínio informal sobre o uso da energia nuclear.

Ensino Superior; (Física, Química, Biologia e Historia). Entrevistas envolvendo cenários com temas: Irradiação de Alimentos; Efeitos da Radiação; Contaminação/ Irradiação; Usos da radioatividade.

Especialistas; Ensino Superior; Questionário; Questionário aplicado antes do inicio de um curso eletivo de radioisótopos. Análise estatística.

Ensino Médio; Que conteúdos CTS relacionados com a energia nuclear, se incluem nos textos analisados.

Ensino Médio; Entrevista.

Não cita público alvo; Descreve como usar o análogo fazendo relação com o decaimento beta.

Ensino Médio; Construção de um guia sobre a história da radioatividade, resíduos radioativos e radiação ionizante.

Ensino Superior; Descreve as regras para determinar a estabilidade de um núcleo e o tipo de emissão radioativa. 


\begin{tabular}{|c|c|c|}
\hline $\begin{array}{l}\text { 20. Williams, } \\
1995 .\end{array}$ & $\begin{array}{l}\text { Apresentar possíveis abordagens para o } \\
\text { tópico resíduo radioativo. }\end{array}$ & $\begin{array}{l}\text { Ensino Superior; Discute diversos conteúdos } \\
\text { de química que pode ser abordado com a } \\
\text { temática. }\end{array}$ \\
\hline $\begin{array}{l}\text { 21. Shultz, } \\
1997 .\end{array}$ & $\begin{array}{l}\text { Descrever analogia para o decaimento } \\
\text { radioativo e a cinética de primeira ordem. }\end{array}$ & $\begin{array}{l}\text { Ensino Médio, Alunos de Química em geral e } \\
\text { calouros; Descreve a analogia e as etapas de } \\
\text { experimento utilizando agitação de dados } \\
\text { inicialmente para determinar o tempo de } \\
\text { meia-vida do ponto de vista qualitativo e } \\
\text { matemático e em seguida utilizando os dados } \\
\text { para construção de um gráfico. }\end{array}$ \\
\hline $\begin{array}{l}\text { 22. Krow; Krow, } \\
1998\end{array}$ & $\begin{array}{l}\text { Aplicar módulo de ensino baseado em } \\
\text { problemas no âmbito científico, político- } \\
\text { social e ético. }\end{array}$ & $\begin{array}{l}\text { Ensino Superior (Educação Continuada); } \\
\text { Atividades interdisciplinares; resolução de } \\
\text { problemas. }\end{array}$ \\
\hline $\begin{array}{l}\text { 23. Crippen; } \\
\text { Curtright, } \\
1998 .\end{array}$ & $\begin{array}{l}\text { Utilizar tecnologia para auxiliar na } \\
\text { aquisição e análise de dados de } \\
\text { decaimento nuclear. }\end{array}$ & $\begin{array}{l}\text { Ensino médio e ensino superior. Apresenta } 4 \\
\text { atividades utilizando instrumento para plotar } \\
\text { gráficos de estabilidade dos núcleos leves; } \\
\text { para isótopos estáveis que ocorrem } \\
\text { naturalmente; série de decaimento do urânio- } \\
238 \text { e sobre a fissão do urânio- } 235 \text {. }\end{array}$ \\
\hline $\begin{array}{l}\text { 24. Olbris; } \\
\text { Herzfeld, } 1999 .\end{array}$ & $\begin{array}{l}\text { Familiarizar os estudantes com reações } \\
\text { nucleares, a geografia geral da tabela de } \\
\text { isótopos nucleares, simulando processos } \\
\text { nucleogênicos através de um jogo. }\end{array}$ & $\begin{array}{l}\text { Ensino Superior, Profissionais e professores. } \\
\text { Descreve o jogo e as suas regras. }\end{array}$ \\
\hline $\begin{array}{l}\text { 25. Hughes; } \\
\text { Zalts, } 2000 .\end{array}$ & $\begin{array}{l}\text { Apresentar atividade de modelagem para } \\
\text { decaimento radioativo. }\end{array}$ & $\begin{array}{l}\text { Não cita público alvo. Apresenta o passo a } \\
\text { passo de como montar um gráfico de } \\
\text { decaimento exponencial para ilustrar sobre o } \\
\text { uso da radioatividade, seus riscos, limitações e } \\
\text { vantagens, utilizando materiais como papel, } \\
\text { tesoura e fita métrica; }\end{array}$ \\
\hline $\begin{array}{l}\text { 26. Tekin, } \\
\text { Nakiboglu, } \\
2006 .\end{array}$ & $\begin{array}{l}\text { Identificar as concepções dos estudantes } \\
\text { do ensino médio sobre conceitos de } \\
\text { química nuclear e conceitos básicos de } \\
\text { química que causam dificuldades para } \\
\text { aprendizagem de conceitos de química } \\
\text { nuclear. }\end{array}$ & $\begin{array}{l}\text { Ensino Médio. Para construção do } \\
\text { instrumento para identificar as concepções } \\
\text { investigou-se os livros didáticos de química } \\
\text { para o ensino médio e observaram-se aulas } \\
\text { em ensino regular. Um questionário com } 7 \\
\text { questões de múltipla escolha, no qual, além } \\
\text { de marcar uma alternativa, os estudantes } \\
\text { deveriam explicar o motivo de sua escolha. }\end{array}$ \\
\hline
\end{tabular}

Fonte: Adaptado de Costa e Moreira (1996)

Tabela 3: Resultado da análise dos artigos referentes à categoria resultados/fatores relevantes/implicações educacionais e conclusão/considerações/sugestões.

\begin{tabular}{|c|c|c|}
\hline $\begin{array}{l}\text { AUTOR(ES)/ } \\
\text { ANO }\end{array}$ & $\begin{array}{l}\text { RESULTADOS/ } \\
\text { FATORES RELEVANTES/ } \\
\text { IMPLICAÇÕES EDUCACIONAIS }\end{array}$ & $\begin{array}{l}\text { CONCLUSÃO/ } \\
\text { CONSIDERAÇÕES/ } \\
\text { SUGESTÕES }\end{array}$ \\
\hline 1. & $\begin{array}{l}\text { Bom nível de atenção dos alunos; produção de } \\
\text { materiais; alunos apresentaram explicações } \\
\text { rudimentares sobre a fissão nuclear. }\end{array}$ & $\begin{array}{l}\text { Atendimento de diversos objetivos } \\
\text { do movimento CTS; } \\
\text { Descentralização do professor; }\end{array}$ \\
\hline 2. & $\begin{array}{l}\text { Os licenciandos acham relevante abordar a historia } \\
\text { para o surgimento da física nuclear; abordar o tema } \\
\text { apenas pelo contexto devido ao grau de dificuldade } \\
\text { do tema. }\end{array}$ & $\begin{array}{l}\text { A formação dos licenciandos deve } \\
\text { possibilitar que eles } \\
\text { compreendam seu imaginário. }\end{array}$ \\
\hline
\end{tabular}


3.

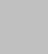

5.

7.

8.

9.

10.

11.

12.

13.

14.

4.
Os livros não contextualizam, apenas relacionam alguns conteúdos com eventos ocorridos; Os autores apresentam concepções de alunos sobre radiação, tais como: "são coisas altamente perigosas, pois podem causar câncer de pele. "Radiação é o desprendimento de partículas de um átomo"; "É a capacidade de um átomo ultrapassar o outro".

Os estudantes desenvolveram habilidade de ilustrar o assunto de forma real e próxima do cotidiano;

O assunto é de contínuo interesse dos estudantes; A abordagem livresca, muitas vezes, não parece suficiente para qualificar as opiniões dos estudantes sobre esse debate:

Apresenta características do modelo relacionando-as a analogias.

Assim como se entende 0 fenômeno da radioatividade como decaimento com o tempo de uma população de núcleo radioativo, no circuito RC em descarga a população de elétrons na placa do capacitor decai com o tempo.

Os alunos criticam o ensino de Física considerando-o voltado para o vestibular e/ou baseado na prática exclusiva de exercícios;

Sugere o trabalho em sala de aula com, por exemplo: Decaimento Alfa e Transmutação Nucelar Detectores de Incêndio; Decaimento Beta: Promécio e Bombeamento de Sangre; Fissão Nuclear;

Motivacionais: Obstáculos transpostos pelos cientistas; Histórico-epistemológicos: Visões de Ciência;

Conceitual: A natureza das radiaç̃̃es.

Os alunos cientificamente orientados mudaram opinião após relatório científico; os socialmente orientados de uma forma geral apresentam uma desconfiança com os dados científicos.

Alunos que se basearam em provas para tomar decisões mudaram sua opinião após ler relatório sobre o assunto; Os alunos não possuem habilidades suficientes para fazer conexões entre o conhecimento aprendido em sala de aula e as questões sociocientificas.

Falta de conhecimento de como a radiação interage com a matéria: "A radiação alfa 'nocauteia' os elétrons"; "A radiação entra na célula (por isso é bloqueada)." "A radiação gama é mais penetrável devido a ser mais energética".

Em geral os alunos apresentam uma atitude positiva frente ao fenômeno radioativo; Ambos os grupos são indiferentes quanto a influência social dos fenômenos radioativos.
A contextualização pode oferecer aos estudantes a possibilidade de identificar o conteúdo a partir de contextos locais;

A abordagem permite transformar o ato de ensinar e aprender química em algo mais agradável e com resultados mais expressivos.

A flexquest satisfez o estudo sobre a radioatividade, no âmbito de suas aplicações.

Utilizar a abordagem em um contexto escolar.

Os modelos possibilitam desenvolver habilidades de visualização e abstração

Interesse assegurado para o ensino superior: formação de professores e cursos específicos de física.

Os alunos não associam a resolução de problemas com a física nuclear;

Sugere a utilização de recursos didáticos como animações e vídeos que tratem do assunto.

- trabalho pretende gerar subsídios relevantes para discussões do professor com seus alunos.

Os leigos cientificamente alfabetizados podem tomar decisões sobre questões que transcendem as tradicionais fronteiras disciplinares.

Sugerem dar espaço para argumentação em sala de aula; Utilização da internet como ferramenta;

Necessidade formativa do professor; Oferta de cursos mais especializados; Utilizar a temática como tema transversal.

Os resultados mostram que existem lacunas em uma suposta alfabetização cientifica que limita os cidadãos na tomada de decisão frente ao problema da energia nuclear. 
15. Os textos apenas informam a questão da produção da energia elétrica em usinas nucleares; Poucos textos apresentam atividades que proponham um debate sobre as vantagens e desvantagens da produção e uso da energia nuclear.

16.

Os resultados são apresentados em termos de porcentagem destacando-se que $37 \%$ dos entrevistados acreditam a propriedade dos materiais radioativos emitirem raios está relacionado com ondas e partículas, $47 \%$ pensam que ao emitir raios os elementos permanecem o mesmo, apenas com menor energia; $32 \%$ pensam que com o passar do tempo os efeitos dos materiais radioativos diminuem ou permanecem constante.

17. A utilização de um análogo é relevante, pois, o decaimento beta é de difícil compreensão por parte dos alunos.

18.

A direção da escola solicitou cópias do guia. $\bigcirc$ guia foi utilizado pelos alunos para discutirem a temática e construírem questões para um debate que ocorreu na escola.

19.

20.

A representação gráfica é componente central no experimento, pois, é apontado como uma fraqueza. O jogo proposto e o decaimento obedecem a mesma lei física. O jogo é adaptável para qualquer público erros encontrados nas regras para determinar esta estabilidade. Apresenta uma questão sobre o tema para seus alunos.

Sugere o ensino de radioatividade em duas etapas: a primeira o ensino das emissões básicas $(\alpha, \beta, \gamma)$; a segunda enfatizando os efeitos.
A energia nuclear não recebe 0 tratamento e a atenção que merece na educação cientifica básica.

Os resultados encontrados provavelmente se devem a influência de fatores sociais, meios de comunicação;

O análogo permite facilmente o estudante compreender o que acontece com um núcleo, ao emitir partícula beta.

A construção do guia foi relevante para a autoestima dos alunos, bem como para o conhecimento de como tomar uma decisão no mundo real; A experiência ilustra que utilizar uma questão social pode fazer a Química além de interessante, relevante para os alunos.

As regras ajudaram aos estudantes a se saírem bem na questão apresentada. Foi utilizado um tempo extra para explicar essas regras, o que aumentou consideravelmente compreensão sobre o assunto

É preciso saber o tema de interesse dos alunos e esforço para encontrar relações entre esses interesses e as aplicações químicas.

A analogia promove uma conexão natural entre o formalismo matemático e o gráfico que descreve o decaimento. Além de promover uma relação intuitiva de probabilidade estatística relacionada ao decaimento, o faz de forma lúdica. 


\begin{tabular}{|c|c|c|}
\hline 22. & $\begin{array}{l}\text { Antes da aplicação do módulo a radioatividade era } \\
\text { ensinada através de palestras; A principio os alunos } \\
\text { não reconheciam os conceitos químicos nos } \\
\text { problemas; Foram apresentados conceitos } \\
\text { relacionados a radiação acompanhados por tarefas, } \\
\text { podendo realizá-las com consulta; Os estudantes } \\
\text { gostaram da atividade como veículo para aprender } \\
\text { sobre radioatividade; }\end{array}$ & $\begin{array}{l}\text { O exercício de aprendizagem } \\
\text { baseado em problemas é flexível } \\
\text { quanto a sua aplicação a diversos } \\
\text { públicos; Os estudantes da } \\
\text { educação } \\
\text { apresentaram continuada } \\
\text { entendimento que os que } \\
\text { assistiram apenas palestras. }\end{array}$ \\
\hline 23. & $\begin{array}{l}\text { Os estudantes desenvolveram conceitos em relação } \\
\text { a decaimento nuclear e uma noção sobre resíduo } \\
\text { radioativo produzido pela fissão nuclear. }\end{array}$ & $\begin{array}{l}\text { Para acompanhar a atividade } \\
\text { pode ser incluída uma maior } \\
\text { investigação sobre a questão } \\
\text { científica, social e tecnológica da } \\
\text { energia nuclear de forma pacífica. } \\
\text { uso de instrumentos } \\
\text { tecnológicos serve como uma } \\
\text { base para integrar disciplinas } \\
\text { científicas e a matemática. }\end{array}$ \\
\hline 24. & $\begin{array}{l}\text { O jogo é apropriado como exercício de laboratório, } \\
\text { deve ser jogado individualmente, onde objetivo é } \\
\text { alcançar o estado de estabilidade, sendo para isso } \\
\text { necessário fazer cálculos de decaimento ou fusão. }\end{array}$ & $\begin{array}{l}\text { Para construção do jogo teve que } \\
\text { ser feitas simplificações; O jogo é } \\
\text { longo, podendo ser resolvido a } \\
\text { questão do tempo com o } \\
\text { aumento do número de } \\
\text { participantes. }\end{array}$ \\
\hline 25. & $\begin{array}{l}\text { Após a construção do gráfico ele pode ser utilizado } \\
\text { para simular algumas situações como, por exemplo, } \\
\text { datação arqueológica. }\end{array}$ & $\begin{array}{l}\text { Com pequenas modificações o } \\
\text { procedimento pode ser adaptado } \\
\text { para situações envolvendo lixo } \\
\text { nuclear. }\end{array}$ \\
\hline 26. & $\begin{array}{l}\text { Algumas concepções identificadas no estudo: } \\
\text { Quanto maior o número atômico e o número de } \\
\text { massa, mais estável é o núcleo; Radiação causa } \\
\text { câncer; Irradiação de alimentos é radioativo; } \\
\text { Radioisótopos são usados para energia porque são } \\
\text { prejudiciais aos seres humanos; A taxa de } \\
\text { decaimento radioativo depende da temperatura. }\end{array}$ & $\begin{array}{l}\text { Um dos obstáculos para a } \\
\text { aprendizagem efetiva da Química } \\
\text { Nuclear é que os conceitos } \\
\text { relacionados a ela são muito } \\
\text { abstratos; Os professores devem } \\
\text { enfatizar a diferença entre reação } \\
\text { química e reação nuclear; O uso } \\
\text { de simulações pode ser uma } \\
\text { forma de superar a dificuldade de } \\
\text { compreensão de conceitos } \\
\text { abstratos; }\end{array}$ \\
\hline
\end{tabular}

Fonte: Adaptado de Costa e Moreira (1996)

Analisando as tabelas, em relação ao público ao qual se deseja alcançar, observamos que do total de trabalhos (vinte e seis), nove (34,6\%) estão direcionados para o ensino superior, quatorze para o ensino básico $(53,8 \%)$, dois sem clara definição do público alvo que deseja atingir $(7,70 \%)$ e um trabalho híbrido, isto é, pode ser utilizado tanto para o nível médio quanto para o superior (3,90\%).

Seria esperado que o tema sobre ensino de radioatividade para o terceiro grau tivesse maior número de artigos, pois a radioatividade é considerada pelos PCN+ (BRASIL, 2006), como um dos temas estruturadores. A presença de poucos trabalhos sobre ensino de radioatividade no ensino superior, em particular, nos periódicos nacionais analisados (1-10, 22, tabela 2) é preocupante, na medida em que a falta de pesquisa em como ensinar esse conteúdo, envolvendo os futuros professores, aponta para a escassa reflexão sobre esta temática que é importante, devido aos diferentes fatores já apresentados, o seu potencial 
de contextualização e de possibilitar o trabalho interdisciplinar (BRASIL, 2006). Pois, entende-se que os futuros professores, antes mesmo de ensinarem esse conteúdo, devem entrar em contato com diferentes possibilidades de abordar esse tema em sua formação inicial. Além disso, a escassa produção nacional voltada para alunos do ensino superior pode estar contribuindo para a deficitária formação dos professores sobre o tema radioatividade já apontada por Tekin e Nakiboglu (2006).

A sistematização dos artigos, feita através da leitura dos textos na íntegra, também permitiu identificar algumas tendências em relação às pesquisas sobre ensino e aprendizagem de radioatividade, quais sejam: proposta de material didático/proposta e análise de estratégias didáticas; estudo de concepções alternativas/ análise de livro didático, discutidas a seguir.

\section{Proposta de material didático/Proposta e análise de estratégias didáticas}

Foram incluídos nesta tendência artigos que apresentam proposta de analogias, modelos, jogos ou módulos didáticos envolvendo a temática radioatividade, bem como de que maneira os professores podem utilizá-la em sala de aula. Também incluem artigos que além de proporem estratégias para o ensino e aprendizagem de radioatividade, refletem sobre os resultados decorrentes da sua aplicação.

Dois artigos apresentam proposta de analogia no estudo de conceitos relacionados à radioatividade, um para o decaimento radioativo (KRAPPAS; BORGES, 1998) e outro para o estudo dos fenômenos de fusão e fissão nuclear (SHAPPO, 2010).

Eichler, Junges e Del-Pino (2006) descrevem e propõem uma estratégia didática utilizando o software Cidade do Átomo para compreensão de temas relacionados a energia nuclear com alunos do ensino médio. Cordeiro e Peduzzi (2010) discutem as implicações educacionais da utilização didática das conferências Nobel. Além disso, algumas propostas temáticas para abordagem da radioatividade é apresentada por Souza e Dantas (2010).

Propostas de jogos e analogias também são encontradas em três dos artigos selecionados na pesquisa internacional. Fortman (1992) utiliza botões de dois tamanhos para propor uma analogia ao decaimento beta, sendo uma alternativa para a compreensão desse processo já que, segundo o autor, os alunos encontram dificuldades em compreendê-lo, pois, estão acostumados a não pensar em elétrons, cargas negativas, dentro do núcleo. Shultz (1997) apresenta uma analogia através de um jogo utilizando dados (semelhantes aos usados em jogos do tipo RPG), estabelecendo uma relação entre a agitação dos dados e o decaimento radioativo. Um jogo mais elaborado é discutido no artigo de Olbris e Herzfeld (1999). A proposta do jogo é levar os alunos a conhecerem melhor os fenômenos da fusão e do decaimento radioativo, exigindo também cálculos para compreensão desses fenômenos ao longo da atividade. Além disso, a estabilidade relativa dos isótopos também compreende um dos conceitos trabalhados neste jogo.

O uso de gráficos para ilustrar o decaimento radioativo é exposto de maneiras distintas por dois artigos analisados. Crippen e Curtright (1998) trazem uma proposta envolvendo a incorporação de instrumentos computacionais para examinar aspectos referentes ao 
decaimento nuclear. Enquanto que uma atividade envolvendo construção de um gráfico exponencial utilizando materiais, como papel, tesoura e cola é tratada por Hughes e Zalts (2000), como uma alternativa para ilustrar discussões sobre a radioatividade, considerando os aspectos positivos e negativos desse tema para a sociedade.

Campbeel (1995) apresenta uma série de regras para determinar a estabilidade nuclear e o decaimento radioativo, como forma de melhorar o entendimento dos alunos em relação a esses tópicos.

$\mathrm{Na}$ pesquisa em periódicos nacionais encontramos 3 artigos que investigam a contribuição de estratégias didáticas para aprendizagem de conceitos referentes a radioatividade. Samagaia e Peduzzi (2004) analisam a utilização de um módulo didático utilizando jogo de papéis (RPG) com alunos do ensino fundamental, recorrendo ao contexto histórico do Projeto Manhattan. No artigo de Vasconcelos e Leão (2012) é apresentado os resultados da utilização de uma estratégia didática, envolvendo a incorporação de uma Flexquest no estudo das aplicações da radioatividade.

Bonneau (1994) e Krow e Krow (1998) trazem o resultado de aplicação de módulo didático abordando conceitos de radioatividade do ponto de vista de seus resíduos, utilizando estratégias como a resolução de problemas e o trabalho em grupo para o desenvolvimento das atividades.

Dos 26 artigos analisados observou-se que vários estudos (70\%) envolvem proposta de material didático, proposição e análise de estratégias didáticas sobre radioatividade. Tal situação é desejável na medida em que o tema é muito abstrato dificultando sua aprendizagem. Por exemplo, alguns estudos propõem analogias como forma de aproximar o conhecimento científico (abstrato) do conhecimento espontâneo (concreto) e possibilitar dessa forma o entendimento dos estudantes. Somando-se a isso, a impossibilidade do conhecimento da química nuclear ser explorada utilizando experimentos macroscópicos com amostras reais e relacionando-os com os conceitos microscópicos, por se tratar de fenômenos que envolvem emissões radioativas. Assim, atividades que favoreçam ações diretas com materiais radioativos não são indicadas, mas são propostos o uso de simulações, softwares, vídeos, dentre outros recursos didáticos, como forma de conduzir os estudantes a entrarem em "contato" com esses fenômenos.

O estudo realizado nesse trabalho referente a essa tendência de pesquisa sugere a necessidade, dos professores em diferentes níveis de ensino, terem acesso às estratégias didáticas propostas nos periódicos analisados, pois representam metodologias instigantes, com materiais interessantes, participação ativa dos estudantes e dinâmica de sala de aula diferenciada, por exemplo, quando comparadas ao ensino tradicional (transmissãorecepção). 
Estudo de concepções alternativas/Análise de livro didático:

Os estudos que refletem sobre a forma como os alunos compreendem questões relacionadas a conceitos de radioatividade, além de como os textos didáticos abordam esse conteúdo também foram encontrados na pesquisa bibliográfica realizada. Medeiros e Lobato (2010) após analisar livros didáticos de Química e Física e as concepções prévias de alunos do ensino médio em relação à contextualização, apresentam o desenvolvimento e a aplicação de um módulo didático contextualizado sobre a temática. A análise do imaginário dos estudantes de licenciatura em Física sobre a inserção da questão nuclear no ensino médio foi discutido em dois artigos analisados. Sorpreso e Almeida (2008) analisam o imaginário quanto ao trabalho com resolução de problema. Já em Sorpreso e Almeida (2010), o imaginário é analisado do ponto de vista da história da ciência.

Na pesquisa internacional, seis dos dezesseis artigos apresentam análise de ideias, raciocínio ou concepções de alunos sobre temas relacionados a radioatividade. Yang e Anderson (2003) e Wu e Tsai (2007) analisaram o raciocínio dos alunos quanto a uma suposta construção de usina nuclear, bem como do uso da energia nuclear do ponto de vista ambiental. Tekin e Nakiboglu (2006) discutem a importância de se conhecer as concepções dos alunos em relação a uma determinada temática para o desenvolvimento de materiais e atividades de instrução. Segundo os autores, embora a Química Nuclear não tenha como foco central o ensino médio, alguns conceitos que são pré-requisitos para seu entendimento (átomo, elemento e nuclídeo, número atômico, número de massa, próton, nêutron e nucleon) são fundamentais na Química, porém muito abstratos, sendo essencial que o professor conheça como o aluno compreende esses conceitos para serem capaz de compreender a Química Nuclear.

Gutierrez et al, (2000), Tiburzi et al, (2004) e Colclough, Lock e Soares (2011), analisaram concepções dos alunos em relação a conceitos de radioatividade. GarcíaCarmona e Criado (2008) mostraram resultados do tratamento da energia nuclear em relação à abordagem CTS em livros didáticos de Física e Química.

Através desse estudo percebeu-se uma quantidade restrita de trabalhos sobre as concepções alternativas dos estudantes em diferentes níveis de ensino e de análise de conceitos relacionados com radioatividade em livros-texto de Química. Nesse sentido, apontamos essas duas linhas de pesquisa como possibilidade de análise e aprofundamento, sendo necessário para isso um desenvolvimento maior de investigações nessa direção.

\section{Considerações finais}

No período analisado, 1990-2012, o estudo revelou poucas investigações sobre o ensino e aprendizagem de radioatividade, especialmente nos periódicos nacionais selecionados. Apesar disso, duas tendências de pesquisa foram identificadas; proposta de material didático/ proposta e análise de estratégias didáticas que incluem analogias, jogos ou módulos didáticos, como por exemplo, uso de uma Flexquest e análise dos resultados 
decorrentes da sua aplicação; estudo de concepções alternativas/análise de livro didático (refletem sobre a forma como os alunos compreendem questões relacionadas a conceitos de radioatividade, além de como os textos didáticos abordam esse conteúdo). No primeiro caso, o estudo realizado sugere a necessidade, dos professores em diferentes níveis de ensino, terem acesso às estratégias didáticas propostas nos periódicos analisados pelas contribuições que podem dar para a prática docente; e no segundo caso, a quantidade restrita de trabalhos sobre as concepções alternativas dos estudantes e de análise de conceitos relacionados com radioatividade em livros-texto de Química, aponta para o desenvolvimento maior de investigações nessa direção, particularmente voltadas para o Ensino Superior de Química.

Finalmente, considera-se que os resultados apresentados nesse estudo não esgotam as discussões encontradas na literatura sobre o ensino e a aprendizagem de radioatividade sendo outras contribuições nesse sentido muito bem-vindas.

\section{Referências}

$\mathrm{BOO}, \mathrm{H}$. K. Students' understandings of chemical bonds and the energetic of chemical reactions. Journal of Research in Science Teaching, v. 35, n. 5, p. 569-581, 1998.

BONNEAU, M. Teaching about radioactivity: using low-level radioactive waste issue in Courtland Country. Journal of Chemical Education, v. 71, n. 8, p. 651-652, 1994.

BRASIL. Secretaria de Educação Básica. Orientações Curriculares Nacionais. Brasília: Ministério da Educação, 2006.

CAMPBELL, M. L. Simples rule for determining nuclear stability and type of radioactive decay. Journal of Chemical Education, v. 72, n. 10, p. 892-893, 1995.

CHASSOT, A.I. Raios X e radioatividade. Química Nova na Escola, v. 2, n. 2, p. 19-22, 1995.

COLCLOUGHA, N. D.; LOCK, R.; SOARES, A. Pre-service teachers' subject knowledge of and attitudes about radioactivity and ionising radiation. International Journal of Science Education, v. 33, n. 3, p. 423-446, 2011.

CORDEIRO, M. D.; PEDUZZI, L. O. Q. As conferências Nobel de Marie e Pierre Curie: a gênese da radioatividade no ensino. Caderno Brasileiro de Ensino de Física, v. 27, n. 3, p. 473-514, 2010.

COSTA, S.S.C., MOREIRA, M.A. Resolução de problemas I: diferenças entre novatos e especialistas. Investigações em Ensino de Ciências, v.1, n.2, p. 176-192, 1996.

CRIPPEN, K. J.; CURTRIGHT, R. D. Modeling nuclear decay: a point of integration between chemistry and mathematics. Journal of Chemical Education, v. 75, n. 11 p. 1434-1436, 1998.

EICHLER, M. L.; JUNGES, F; DEL PINO; J. C. Cidade do Átomo: Debate escolar sobre energia nuclear. Física na Escola, v. 7, n. 1, p. 17-21, 2006.

FORTMAN, J. J. An Overhead projector demonstration of nuclear beta emission. Journal of Chemical Education, v. 69, n. 2, p. 162-163, 1992. 
GARCÍA-CARMONA, A.; CRIADO, A. M. Enfoque cts en la enseñanza de la energía nuclear: análisis de su tratamiento en textos de física y química de la eso. Enseñanza de las ciencias, v. 26, n.1, p. 107124, 2008.

GutiérReZ, E. E.; CAPuANO, V.C.; PERROTTA, M.T.; DE LA FUente, A.M. FOlLARI, B.D.R. Qué piensan los jóvenes sobre radiactividad, estructura atómica y energía nuclear? Enseñanza de las ciencias, v. 18 n. 2, p.247-254, 2000.

HUGHES, E. A.; ZALTS, A. Radioactivity in the classroom. Journal of Chemical Education, v. 77, n. 5, p. 613-614, 2000.

KRAPAS, S.; BORGES, A. M. Decaimento radioativo: uma analogia para o circuito RC. Caderno Catarinense de Ensino de Física, v. 15, n. 1, p. 47-58, 1998.

KROW, G. R.; KROW, J. B. Low-level radioactive waste disposal: an exercise in dealing with pollution. Caderno Catarinense de Ensino de Física, v. 75, n. 12, p. 1583-1584, 1998.

LIMA, R. S., PIMENTEL, L. C. F.; AFONSO, J. C. O despertar da radioatividade ao alvorecer do século XX. Química Nova na Escola, v. 33 n. 2, p. 93-99, 2011.

MEDEIROS, M. A.; LOBATO, A. C. Contextualizando a abordagem de radiações no ensino de Química. Ensaio: pesquisa em educação em ciências, v.12, n.3, p.65-84, 2010.

OLBRIS, D. J.; HEZFELD, J. Nucleogenesis! A game with natural rules for teaching nuclear synthesis and decay. Journal of Chemical Education, v. 76, n. 3 p. 349-352, 1999.

PASSOS, M.H.S.; SOUZA, A.A. Química Nuclear e Radioatividade. Campinas, SP: Editora Átomo, 2010. RIBEIRO, A.A. e GRECA, I.M. Simulações computacionais e ferramentas de modelização em Educação Química: uma revisão de literatura publicada. Química Nova, v. 26, n. 4, p. 542-549, 2003.

SCHAPPO, M. G. Um modelo concreto para o estudo da estabilidade nuclear no Ensino Médio. Física na Escola, v. 11, n. 2, p. 22-26, 2010.

SCHULTZ, E. Dice-shaking as an analogy for radioactive decay and first-order kinetics. Journal of Chemical Education, v. 74, n. 5 p. 505-507, 1997.

SIQUEIRA, A. Práticas Interdisciplinares na Educação Básica: Uma revisão bibliográfica - 1970 -2000. Educação Temática Digital, v. 3, n.1, p. 90-97, 2001.

SORPRESO, T. P.; ALMEIDA, M. J. P. M. Aspectos do imaginário de licenciandos em Física numa situação envolvendo a resolução de problemas e a questão nuclear. Caderno Catarinense de Ensino de Física, v. 25, n. 1, p. 77-98, 2008.

SORPRESO, T. P.; ALMEIDA, M. J. P. M. Discursos de licenciandos em física sobre a questão nuclear no ensino médio: foco na abordagem histórica. Ciência \& Educação, v. 16, n. 1, p. 37-60, 2010.

SOUZA, M. A. M; DANTAS, J. D. Fenomenologia nuclear: uma proposta Conceitual para o ensino médio. Caderno Catarinense de Ensino de Física, v. 27, n. 1, p. 136-158, 2010.

TEIXEIRA, P. M. M.; MEGID-NETO, J. Investigando a pesquisa educacional: um estudo enfocando dissertações e teses sobre o ensino de biologia no Brasil. Investigações em Ensino de Ciências, v. 11, n. 2, p. 261-282, 2006. 
TEKIN, B. B.; NAKIBOGLU, C. Identifying student's misconceptions about nuclear chemistry. A study of Turkish high school students. Journal of Chemical Education, 83, n. 11 p. 1712, 2006.

TIBURZI, M.D.C.; PLIEGO, O. H.; CONTINI, L.; ODETTI, H.; RENÉ, G. Las actitudes de los estudiantes universitarios hacia el fenómeno radiactivo, la energía nuclear y sus aplicaciones. Educación Química, v.15, n. 2, p. 142-148, 2004.

VASCONCELOS, F. C. G. C.; LEÃO, M. B. C. Utilização de recursos audiovisuais em uma estratégia flexquest sobre radioatividade. Investigações em Ensino de Ciências, v. 17, n. 1, p. 37-58, 2012.

WILLIAMS, D. H. Success and techniques associated with teaching the chemistry of radioactive wastes. Journal of Chemical Education, v. 72, n. 11, p. 971-973, 1995.

WU, Y.; TSAI, C. High School Students' Informal Reasoning on a Socio-scientific Issue: qualitative and quantitative analyses. International Journal of Science Education, v. 29, n. 9, p. 1163-1187, 2007.

XAVIER, A.M.; LIMA, A.G.; VIGNA, C.R.M.; VERBI, F.M; BORTOLETO, G. G.; GORAIEB, K.; COLLINS, C. H.; BUENO, M.I.M.S. Marcos da história da radioatividade e tendências atuais. Química Nova, v. 30, n. 1, p. 83-91, 2007.

YANG. F.; ANDERSON, O.R. Senior high school students' preference and reasoning modes about nuclear energy use. International Journal of Science Education, v. 25, n. 2, p. 221-244, 2003. 